\title{
A PRODUÇÃO DE BIODIESEL E A QUESTÃO AGRÁRIA: PERSPECTIVAS E DESDOBRAMENTOS
}

Thadeu Henrique Witkowski, Munir Jorge Felicio

Universidade do Oeste Paulista - UNOESTE. E-mail: agrothadeu@homail.com

\section{RESUMO}

Este trabalho pretende compreender como a produção de biocombustível pode ser um desdobramento da questão agrária. Essa reflexão embasada em levantamentos teóricos, em que estabelecemos diálogos entre diversos autores abrangente à contextualização da questão agrária e o Programa Nacional de Produção e Uso de Biodiesel, permitiu evidenciar a real concentração da produção de matéria prima para o abastecimento da produção de biodiesel, bem como entender se as proposta de consolidação da produção de biodiesel pela agricultura familiar são instrumentos de uma política emancipatória, ou meramente um elo de dependência caracterizando em uma política de subordinação.

Palavras-chave: Campesinato, capitalismo agrário, questão agrária, biodiesel, política pública

\section{A BIODIESEL PRODUCTION AND AGRICULTURAL THE QUESTION: PROSPECTS AND DEVELOPMENTS}

\begin{abstract}
This work aims to understand how biofuel production can be an offshoot of the agrarian question. This reflection grounded in theoretical surveys that establish dialogues between various authors comprehensive contextualization of the agrarian question and the National Program for Production and Use of Biodiesel, has highlighted the real concentration of production of raw materials for the supply of biodiesel production, as well how to understand whether the proposed consolidation of biodiesel production by family farmers are instruments of an emancipatory politics, or merely a link dependency characterizing a policy of subordination.

Keywords: Peasantry, agrarian capitalism, agrarian question, biodiesel, public policy
\end{abstract}


INTRODUÇÃO

O capital não admite nenhuma limitação, assim, excluindo a produção e os meios de produção que restrinja o seu modo de atuação. (LUXEMBURG, 2007)

Esta afirmação, em consonância com o texto de Felício (2012), confirma a constituição da questão agrária formada por dois elementos: o capital e o campesinato. O capital representado pelo agronegócio e o imperialismo do seu desenvolvimento tecnológico, econômico e concentração latifundiária, também, caracterizado por investimentos em capital fixo que criam uma capacidade potencial para aumentos regulares da produtividade e do consumo da massa, e, do outro lado, o campesinato simbolizado pelo resgate das raízes da agricultura camponesa/familiar, promovendo o ressurgimento da produção artesanal.

O estudo da questão agrária propicia compreender a organização dos trabalhadores explorados e expropriados que foram postos às margens da lógica do "desenvolvimento", como o objetivo de romper a barreira excludente imposta pelo latifúndio e a fusão singular do Estado com o capital (SOBREIRO FILHO. 2012).

Esse cenário é importante para se estudar os desdobramentos da questão agrária tendo o biodiesel como uma produção alternativa que pode alavancar o desenvolvimento.

\section{METODOLOGIA}

A metodologia aplicada na presente pesquisa dá-se por meio de um levantamento bibliográfico, o que favoreceu a realização de diálogos entre diversos autores abrangente à contextualização da questão agrária e o Programa Nacional de Produção e Uso de Biodiesel, visando entender as relações entre a adoção pelo Estado de um novo modelo de produção energética, sob a vertente de valorização do meio ambiente e a reprodução social de forma sustentável, tendo pano de fundo o campesinato como protagonista.

\section{RESULTADOS}

Com o levantamento das literaturas, concepções, diálogos e questionamentos dos autores, concluímos que o Governo Federal passa a desenvolver programas e políticas setoriais, com o discurso em defesa ao modelo de desenvolvimento territorial e fortalecimento da agricultura familiar, exemplo destas ações setoriais é a edição do Programa Nacional de Produção e Uso de Biodiesel, da Lei no 11.097 de 13 de maio de 2005 e do Decreto Medida Provisória no 647/14 que dispõe sobre a introdução do biodiesel na matriz energética brasileira, fixando em $6 \%$ o volume percentual mínimo obrigatório de adição de biodiesel ao diesel comum em território nacional. 
Assim o Programa Nacional de Produção e Uso do Biodiesel e seus desdobramentos, ao discurso do Estado assume importante papel na promoção de inclusão socioeconômica na cadeia produtiva do biocombustível.

Porém defrontamo-nos, que essa política energética não é uma novidade para Brasil, uma vez que já na década de 70, o Estado brasileiro desenvolveu mecanismos de manutenção para uma política como o Proálcool e Pro-óleo.

Entrementes, é bom evidenciar que desde o início, estes programas foram desenvolvidos para o benefício de agroindustriais que detinham também o poderio político, assim estabelecendo a fusão singular do Estado com o capital.

\section{DISCUSSÕES}

De acordo com Felício (2013, p. 187) “desde a década de 70 do século XX as conferencias mundiais chamam a atenção para a insustentabilidade do modelo de desenvolvimento em vigor no globo", o que assevera os relatos de segundo Pessoa et al. (2007), que destacam que estas articulações recentemente foram manifestadas por um grupo de cientistas reunidos pela ONU no Painel Intergovernamental de Mudanças Climáticas - IPCC, que resultando em um relatório, apresentou apontamentos dos danos ocasionados pelo aumento da temperatura na Terra, além de estimar as catástrofes que irão ocorrer caso não ocorra uma significativa redução das emissões dos gases causadores de efeito estufa.

Na perspectiva de discutir a complexidade das questões ambientais, Felício (2013, p. 187), destaca que "vários pesquisadores se debruçaram sobre os desdobramentos da problemática ambiental procurando contribuir com suas análises". Neste contexto, a problemática ambiental ganha aspecto político e econômico, despertando no cenário mundial a relevância no desenvolvimento de novas tecnologias que contribuam ecologicamente para um mundo sustentável e menos poluído (VIOMAR, 2013).

Viomar (2013) destaca que na busca por fonte limpas de energia, o biodiesel vem sendo apontado como o principal substituinte ao diesel de petróleo. A grande atenção dada por diversos pesquisadores a este biocombustível é bem justificada pela diminuição incontestável na emissão de poluentes.

Pafunda et al. (2009, p. 2) descreve que nesta discussão "o discurso governamental brasileiro elege o biodiesel como sendo um fator preponderante de solução à futura escassez energética, que viabiliza, inclusive, a inclusão social ao gerar trabalho e renda para a agricultura familiar". 
Pessoa et al. (2007, p. 115) ainda destaca que "as energias renováveis dos trópicos anunciam novas perspectivas para países pobres e em desenvolvimento, e ainda possibilitam se vislumbrar a desejada sustentabilidade energética para países ricos".

Assim, motivado pela retomada da discussão da temática do biodiesel, coordenada pelo Ministério da Ciência e Tecnologia em 2002, o governo federal, criou um grupo interministerial em 2003 para debruçarem-se sobre medidas para otimização das viabilidades econômica e competitiva para uma consolidação do biodiesel como matriz energética.

Goldemberg et al. (2008), destaca que dois anos após a retomada da discussão do biodiesel, em dezembro de 2004, o governo federal lança través do grupo interministerial o Programa Nacional de Produção e Uso do Biodiesel - PNPB, objetivando a implementação da cadeia de produção de biodiesel no Brasil.

As principais diretrizes do PNPB são i - implantação de um programa sustentável, promovendo a inclusão social através da geração de renda e emprego; ii - a garantia de preços competitivos, qualidade e suprimento; iii - produção de biodiesel a partir de diferentes fontes oleaginosas, fortalecendo as potencialidades regionais para a produção de matéria prima. (BRASIL, 2004)

Resultado do PNPB, a edição do Decreto 5.297, de 06/12/2004, cria Selo Combustível Social, concedido pelo Ministério do Desenvolvimento Agrário ao produtor de biodiesel que adquire matérias primas de famílias de pequenos agricultores cadastradas em cooperativas e enquadradas no Programa Nacional de Fortalecimento da Agricultura Familiar - PRONAF, promovendo assim, a inclusão social, a geração de postos de trabalho e renda para a agricultura familiar.

É importante destacar que a introdução efetiva do biodiesel como matriz energética no Brasil dá-se a partir da edição da Lei no. 11.097 de 13 de maio de 2005.

O presente dispositivo legal instituí a Agência Nacional do Petróleo, Gás Natural e Biocombustíveis - ANP, com a finalidade de promover a regulação, a contratação e a fiscalização das atividades econômicas integrantes da indústria do petróleo, do gás natural e dos biocombustíveis, e define o biodiesel como:

XXV - Biodiesel: biocombustível derivado de biomassa renovável para uso em motores a combustão interna com ignição por compressão ou, conforme regulamento, para geração de outro tipo de energia, que possa substituir parcial ou totalmente combustíveis de origem fóssil. (BRASIL, 2005) 
Goldemberg et al. (2008, p. 32) ressaltam que “a Lei no. 11.097 estabeleceu que a partir de 2008, que todo óleo diesel comercializado no Brasil deveria conter 2\% de biodiesel (B2), e que em 2013, ao óleo diesel dever-se-ia adicional 5\% deste combustível (B5)".

Atualmente, com a publicação da Medida Provisória no 647, de 28 de maio de 2014, o percentual de adição obrigatória de biodiesel ao óleo diesel comercializado ao consumidor final é de $6 \%$, (B6) e 7\%, a partir de $1^{\circ}$ de novembro de 2014, (B7). (BRASIL, 2014)

A Medida Provisória no 647 define também que:

Art. $3^{\circ} \mathrm{O}$ biodiesel necessário à adição obrigatória ao óleo diesel deverá ser fabricado preferencialmente a partir de matérias-primas produzidas pela agricultura familiar, e caberá ao Poder Executivo federal estabelecer mecanismos para assegurar sua participação prioritária na comercialização no mercado interno. (BRASIL, 2014)

Ou seja, este dispositivo legal, favorece e reafirma as garantias da participação da agricultura família no processo de produção de biodiesel previsto no Programa Nacional de Produção e Uso do Biodiesel.

Pessoa et al. (2007) e Goldemberg et al. (2008), destacam que a multiplicidade de fontes de extração da matérias-primas como o dendê, a mamona, o algodão, a soja, o pinhão-manso, a macaúba, o girassol e amendoim corroboram com as políticas públicas de favorecimento da agricultura familiar na produção de biocombustível.

Assim, o Programa Nacional de Produção e Uso do Biodiesel traz a perspectiva de promover a redução das disparidades socioeconômicas regionais do país por meio da inclusão social de agricultores familiares no fornecimento de matérias-primas para a produção de biodiesel.

Porém, é importante que façamos uma análise mais profunda deste contexto de produção de biodiesel para que possamos elucidar realmente em quais mãos concentra-se a soberania da produção nacional de biodiesel

Locatel e Azevedo (2008) dissertam que:

A produção de álcool combustível no Brasil está diretamente relacionada à monocultura, que historicamente esteve vinculada ao latifúndio, fato que marca de forma negativa a histórica agrária do país. Além de contribuir para a manutenção da estrutura fundiária extremamente concentrada, ainda tem um custo social imposto ao conjunto da sociedade. As relações de trabalho predominantes no setor canavieiro, com trabalho sazonal e remunerado por produtividade, possibilitam a superexploração do trabalho, como salários aviltantes, o que, não raro, tem levado trabalhadores à morte por exaustão. 
Não obstante a realidade da produção de etanol, a produção de biodiesel brasileira também se concentra nas mãos do capital representado pelo agronegócio da soja e complexos agroindustriais frigoríficos.

Igualmente a fusão do Estado e capital sucroalcooleiro, Barreto e Thomaz Junior (2012), descreve que diante a condução pelo fortalecimento da matriz energética brasileira e o reconhecimento internacional quanto à a produção de fontes de energia limpa e renovável, constitui-se mais um cenário de aliança entre políticos, entidades de classe, capitalistas e latifundiários, somando-se ainda os financiamentos bilionários com recursos disponibilizados pelo Estado, através no BNDES e créditos agrícolas.

Segundo o portal do Ministério da Agricultura - MAPA, para o plano safra 2013/2014 fora disponibilizado cerda de 136 bilhões de reais, sendo $R \$ 97,6$ bilhões para financiamentos de custeio e comercialização e $\mathrm{R} \$ 38,4$ bilhões para os programas de investimento, resultando no maior volume financeiro já lançado no Brasil para o financiamento agrícola.

De acordo com os indicadores agropecuários da CONAB (2014), a safra 2013/2014 será representada por 56.861,1 hectares de área de cultivo de grãos, favorecendo uma produção de 191.566,3 mil toneladas de grãos, em destaque a produção de soja, assume um importante filão na produção de grão nacional, representado 86,1 milhões de toneladas.

Em consonancia com o Ministério de Minas e Energia, a soja assume um imporante papel como a principal materia prima para produção de biodiesel, respondendo por $73,1 \%$ da demanda total da fabricação de biodiesel no Brasil.

\section{CONCLUSÃO}

Evidenciado que a concentração da produção de matéria prima para o abastecimento da produção de biodiesel estringem-se nas mãos de grandes latifundiários, aqui caracterizados como capital agrário,

Dessa forma, evidenciamos que a consolidação da produção de biodiesel não se da pela agricultura familiar, e sim por um setor produtivo concentrador de renda e terras representada pelo capital sojicultor e agroindustrial.

No entanto, experiências como a proposta de consolidação da produção de biodiesel pela agricultura familiar corre o sério risco de transformar uma política emancipatória em um verdadeiro elo de dependência perante grandes empresas agrícolas, que controlam os preços, o processamento e a distribuição da produção, caracterizando em uma política de subordinação. 
O que resta é a subordinação da agricultura familiar na legitimação do capital em valer-se das benesses e reconhecimento atribuídos pela legislação e práticas de mercado, estabelecendo assim mais uma face da questão agrária, agora representada pelo contexto da produção de biodiesel.

\section{REFERÊNCIAS}

APROBIO, Associação dos Produtores de Biodiesel do Brasil. Boletim Mensal dos Combustíveis Renováveis. ed. n. 76, maio. 2014. Disponível em: <http://www.aprobio.com.br/>. Acesso em: 12 de junho de 2014.

BARRETO, Maria Joseli; THOMAZ JUNIOR, Antônio. Os impactos territoriais da monocultura da cana-de-açucar no Pontal do Paranapanema - SP. Revista Pegada, v. 13, n, 02. Dezembro. 2013.

BRASIL. Decreto no. 5.297, 06 de dezembro de 2004. Dispõe sobre os coeficientes de redução das alíquotas da Contribuição para o PIS/PASEP e da COFINS incidentes na produção e na comercialização de biodiesel, sobre os termos e as condições para a utilização das alíquotas diferenciadas, e dá outras providências. Brasília, 2004.

Lei no. 11.097, 13 de maio de 2005. Dispõe sobre a introdução do biodiesel na matriz energética brasileira; altera as Leis $\mathrm{n}^{\mathrm{0s}}$ 9.478, de 6 de agosto de 1997, 9.847, de 26 de outubro de 1999 e 10.636, de 30 de dezembro de 2002; e dá outras providências. Brasília, 2005.

. Medida Provisória no 647, 28 de maio de 2004. Dispõe sobre a adição obrigatória de biodiesel ao óleo diesel comercializado ao consumidor final, e dá outras providências. Brasília, 2014.

. Programa Nacional de Produção e Uso de Biodiesel. SAF-MDA. 2004

FELÍCIO, Munir Jorge. Apontamentos de Epistemologia Ambiental. Revista GEOAMBIENTE ON-LINE. Jatai-GO. №. 21. Jul-Dez. 2013.

GOLDEMBERG, José. et al. Bioenergia no Estado de São Paulo: situação atual, perspectivas, barreiras e propostas. São Paulo, ed. Imprensa Oficial do Estado de São Paulo, p. 152, 2008.

HUBERMAN, Leo. História da Riqueza do Homem. 15a edição. Rio de Janeiro: Zahar Editores. 1979.

LOCATEL, Celso D; AZEVEDO, Francisco Fransualdo de. Desenvolvimento rural, política nacional de biocombustíveis e o mito da inclusão social no campo brasileiro. In: Colóquio Internacional de Geocrítica, 10. Barcelona. 2008. Disponível em: <http://www.ub.edu/geocrit/-xcol/313.htm>. Acessado em 12 de julho de 2014.

LUXEMBURG, Rosa. A Acumulação do Capital. São Paulo. Editora EdicionesAkal. 2007.

PAFUNDA, Rosana Akemi. et al. $\mathbf{O}$ avanço do biodiesel no Pontal do Paranapanema: uma análise da participação dos assentados na produção de agrocombustíveis. In: Encontro Nacional de Geografia Agraria, 19. São Paulo. 2009, p. 1-14. 
PESSOA, Valdemberg M. do N.et al. $\mathbf{O}$ biodiesel como elemento de desenvolvimento sustentável no semi-árido potiguar. Revista Holos, Ano 23, v. 03, p. 113-125. 2007. Disponível em: <http://www2.ifrn.edu.br/ojs/index.php/HOLOS/article/viewFile/134/122>. Acesso em: 01 de maio de 2014.

SOBREIRO FILHO, José. A luta pela terra no Pontal do Paranapanema:história e atualidade. Revista Geografia e Questão, v. 05, n. 01, p. 83-114, 2012

VIOMAR, Aline. Estudo das variáveis da produção de biodiesel. 2013.Dissertação de Mestrado Universidade Estadual do Centro-Oeste. Guarapuava - PR. 2013 